\title{
Commentary: Window of brain protection after congenital heart surgery-Is it still open?
}

\author{
William T. Mahle, MD
}

\footnotetext{
From Clinical Research Program for Cardiovascular Research, Children's Healthcare of Atlanta, Atlanta, Ga; and the Division of Cardiology, Department of Pediatrics, Emory University School of Medicine, Atlanta, Ga. Disclosures: Author has nothing to disclose with regard to commercial support.

Received for publication March 15, 2019; accepted for publication March 15, 2019; available ahead of print May 7, 2019.

Address for reprints: William T. Mahle, MD, 2835 Brandywine Rd, Suite 400, Atlanta, GA 30341 (E-mail: mahlew@kidsheart.com).

J Thorac Cardiovasc Surg 2019;158:880-1

$0022-5223 / \$ 36.00$

Copyright (c) 2019 by The American Association for Thoracic Surgery

https://doi.org/10.1016/j.jtcvs.2019.03.070
}

Near-infrared spectroscopy has been adopted by many congenital heart programs during the last 2 decades. This modality allows one to monitor regional oxygenation at the bedside. The frequent clinical observation of low regional cerebral oxygenation $\left(\mathrm{rSO}_{2}\right)$ in the postoperative period leaves the bedside clinician to ponder about the long-term implication of this finding. Patients with congenital heart disease, particularly those with single-ventricle physiology, will often have $\mathrm{rSO}_{2}$ of less than $50 \%$. The consequences of this finding on a child's developmental trajectory remain poorly characterized. In their article in this issue of the Journal, Claessens and colleagues ${ }^{1}$ attempt to pair the $\mathrm{rSO}_{2}$ data with simultaneous blood pressure values to provide insights not only into regional cerebral perfusion but also into the potential role of cerebral autoregulation. The investigators seek to determine whether indices of cerebral oxygenation and autoregulation might be related to the development of white matter injury, a potential marker of subsequent neurodevelopmental impairment.

The study demonstrated, as other investigators before them have as well, that cerebral autoregulation is impaired in many children after congenital heart surgery. The study failed, however, to show a relationship between either $\mathrm{rSO}_{2}$ or autoregulation with the development of white matter injury, as measured by magnetic resonance imaging. The lack of association between these indices and white matter injury raises as many questions as it answers. It is possible that the relatively heterogeneous population in this study may have made it more difficult to discern associations. At least one previous study has suggested that prolonged low $\mathrm{rSO}_{2}(<45 \%$ for $>180$ minutes $)$ is associated with the development of new white matter injury on magnetic resonance imaging scanning. ${ }^{2}$ Given such conflicting data, one cannot say definitively that low $\mathrm{rSO}_{2}$ or impaired cerebral autoregulation do not affect brain injury. It is also important to realize that the true significance of white matter injury after testing. outcome.

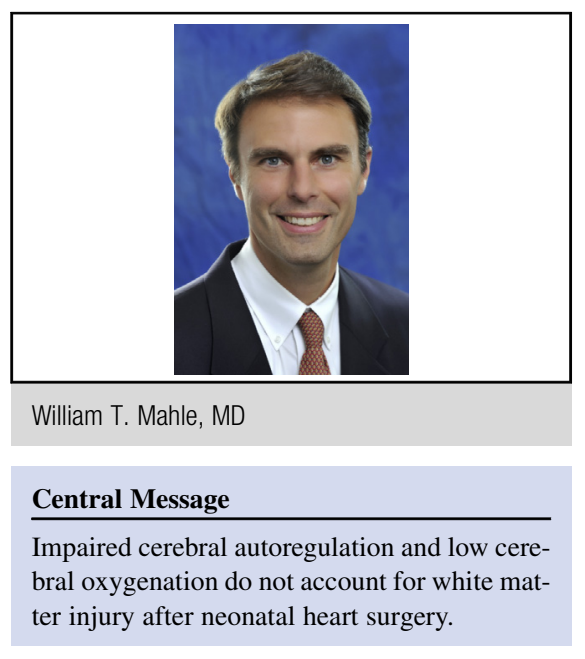

See Article page 867.

congenital heart surgery is not well established. White matter injury described in the congenital heart surgery population is often relatively mild compared with that seen in the preterm population and has been shown to resolve with time. The relationship of white matter injury to subsequent developmental test scores has been variable, with a number of investigators failing to show a strong association. It is possible that impaired $\mathrm{rSO}_{2}$ or impaired autoregulation may indeed affect developmental outcomes without demonstrating a clear association with the white matter injury seen in the postoperative period. Importantly, one team of investigators found that cerebral tissue oxygenation index, which can be considered a surrogate for cerebral autoregulation, has been shown to correlate with developmental test scores in the congenital heart disease population. ${ }^{3}$ Accordingly, Claessens and colleagues ${ }^{1}$ would do well to follow this cohort through time and consider formal developmental

For the near term, it is unclear how much focus clinicians should place on cerebral $\mathrm{rSO}_{2}$ in terms of perioperative brain protection. The work by Claessens and colleagues ${ }^{1}$ adds to the growing but important literature that provides insights into the early operative and postoperative hemodynamics of the process of brain injury and subsequent developmental

\footnotetext{
References

1. Claessens NHP, Jansen NJG, Breur JMPJ, Algra SO, Stegeman R, Alderliesten T, et al. Postoperative cerebral oxygenation was not associated
} 
with new brain injury in infants with congenital heart disease. J Thorac Cardiovasc Surg. 2019;158:867-77.e1.

2. Dent DL, Spaeth JP, Jones BV, Schwartz SM, Glauser TA, Halinan B, et al. Brain magnetic resonance imaging abnormalities after the Norwood procedure using regional cerebral perfusion. J Thorac Cardiovasc Surg. 2005;130:1523-30.
3. Spaeder MC, Klugman D, Skurow-Todd K, Glass P, Jonas RA, Donofrio MT. Perioperative near-infrared spectroscopy monitoring in neonates with congenital heart disease: relationship of cerebral tissue oxygenation index variability with neurodevelopmental outcome. Pediatr Crit Care Med. 2017;18:213-8. 